\title{
LH, FSH and ovulation rate in ewes treated with exogenous oestradiol
}

\author{
S. Atkinson*, N. R. Adams and G. B. Martin \\ CSIRO Division of Animal Production, Private Mail Bag, Wembley, WA 6014, Australia
}

\begin{abstract}
Summary. In two experiments, mature Merino ewes were fitted with subcutaneous implants containing oestradiol-17 $\beta$ or empty implants (control). Peripheral concentrations of LH and FSH were measured during luteal and follicular phases, which were synchronized by means of intravaginal progestagen-impregnated sponges. The ovulation rates of the ewes were determined by laparoscopy, 1 week after luteolysis. In Exp. 1 , small implants $(3 \mathrm{~mm})$ decreased the LH pulse frequency before luteolysis. In the ewes with oestradiol implants, the amplitude of the preovulatory surge of LH was reduced and the onsets of the LH and FSH surges were delayed. There was no effect of oestradiol on LH baseline, LH pulse amplitude or in the concentration of FSH during the luteal or follicular phases. In Exp. 2, larger implants $(10 \mathrm{~mm})$ were inserted for the luteal, follicular, or luteal + follicular phases. The control ewes had empty implants. In the ewes with oestradiol implants, $\mathrm{LH}$ pulse frequencies were decreased during the luteal phase. This decrease persisted throughout the follicular phase, even though the oestradiol implants had been removed. There were no differences in the other measures of LH or FSH in the luteal or follicular phases. Ovulation rates were not affected by oestradiol treatment in either experiment, indicating that the regulation of LH pulse frequency is not a critical factor in the determination of ovulation rate in ewes. This was supported by retrospective analysis of the gonadotrophin profiles of single and twin-ovulating ewes, in which all measures of LH were similar between the two groups. However, twin-bearing ewes had slightly higher circulating concentrations of FSH during the luteal phase. As the difference in FSH was not large $(13 \%)$, and it disappeared after luteolysis, it is difficult to postulate that FSH plays a major role in the final selection of the preovulatory follicle(s) in the ewe.
\end{abstract}

Keywrords: ovulation rate; LH; FSH; oestradiol; sheep

\section{Introduction}

There are conflicting reports on the roles of luteinizing hormone $(\mathrm{LH})$ and follicle-stimulating hormone (FSH) in determining the ovulation rate of ewes. Bindon (1984) compared fecund Booroola and normal Merino ewes and concluded that ovulation rate was independent of the amount and pattern of LH secreted in the preovulatory period. Similarly, some researchers examining the nutritional stimulation of ovulation rate have found no effects on pituitary $\mathrm{LH}$ content or basal plasma LH concentrations before or after the preovulatory LH surge (Haresign, 1981; Rhind et al., 1984). Conversely, others have reported that mean basal concentrations and pulse frequency of LH were significantly higher in ewes with a higher ovulation rate (Thomas et al., 1984; Wallace et al., 1985).

The same confusion persists with regard to the role of FSH; Findlay \& Cumming (1976) found that ovulation rate was not correlated with FSH and Rhind et al. (1986) concluded that ovulation

*Present address: Newborn Research Lab, 2538 The Mall, University of Hawaii, Honolulu, Hawaii 96822, USA. 
rate is not a function of FSH concentration at any time of the cycle. Contrary to this, Rhind \& McNeilly (1986) suggested that ovulation rate is controlled through FSH and McNatty et al. (1985) have demonstrated that a $20-40 \%$ increase in the normal concentration of FSH during the $48 \mathrm{~h}$ before luteolysis increases twinning.

Oestradiol is also believed to be involved in the control of ovulation rate. Immunization against oestradiol or oestrone, during the luteal or follicular phase, leads to an increase in the frequency of LH pulses and an increase in ovulation rate (Scaramuzzi \& Radford, 1983; Pathiraja et al., 1984). Conversely, exogenous oestradiol, in the form of an implant, is known to decrease the ovulation rate of ewes (Webb \& Gauld, 1987). It might be expected that oestradiol would reduce the frequency of LH pulses during the luteal phase (Martin et al., 1983).

On the basis of these results, it was considered that the changes in ovulation rate caused by treatment with, or immunization against, oestradiol could be caused by changes in the frequency of LH pulses. The objective of this study was therefore to determine whether low doses of exogenous oestradiol could affect LH and/or FSH secretion without altering the ovulation rate of cyclic ewes. A retrospective analysis of single and twin-ovulating ewes was also undertaken to identify differences in circulating concentrations of gonadotrophins.

\section{Materials and Methods}

\section{Experiment 1}

The purpose of this experiment was to determine the effects of low doses of exogenous oestradiol on (a) the circulating concentrations of LH and FSH during the luteal and follicular phases and (b) the timing of the preovulatory gonadotrophin surges.

Animals and treatment groups. Mature Merino ewes were randomized into two groups. The 30 ewes were housed indoors in individual pens. One group had $3 \mathrm{~mm}$ oestradiol implants inserted subcutaneously while the other group had empty implants inserted. The implants were prepared by sealing crystalline oestradiol-17 $\beta$ or air (for the control group) in Silastic tubing (i.d. $1.57 \mathrm{~mm}$, o.d. $3.18 \mathrm{~mm}$ : 601-285 Dow Corning, Midland, MI, USA). Assays sufficiently sensitive to estimate the effect of these implants on peripheral concentrations of oestradiol in ewes were not available, so the release rate of oestradiol from these implants was estimated in vitro by measuring the release of $\left[{ }^{3} \mathrm{H}\right]$ loestradiol into $0.1 \%$ bovine serum albumin in saline at $37^{\circ} \mathrm{C}$, and was calculated as $0.19 \mu \mathrm{g} / 1.0 \mathrm{~mm}$ per $24 \mathrm{~h}$.

All ewes also received intravaginal medroxyprogesterone acetate sponges (Repromap, Upjohn, Kalamazoo, MI, USA) to synchronize oestrus. The sponges were fitted at the same time as the implants and remained in place for 12 days. At 7 days after the sponges were removed, the implants were removed and the ovaries were examined by laparoscopy under local anaesthesia.

Blood sampling for hormone analysis. At 4 days before the intravaginal sponges were removed, blood was sampled every $15 \mathrm{~min}$ for $8 \mathrm{~h}$, through indwelling jugular cannulae inserted the previous day. These samples were considered to be representative of the luteal phase and were analysed for the concentration of LH. At $12 \mathrm{~h}$ after sponge removal (i.e. during the follicular phase), blood was again sampled at 15 -min intervals for $8 \mathrm{~h}$. At the end of this sampling period, blood samples were collected at 2-h intervals for $16 \mathrm{~h}$ and then at $1-\mathrm{h}$ intervals for a further $24 \mathrm{~h}$. These samples were used to time the preovulatory surges of gonadotrophins.

In addition, a blood sample was collected daily from each ewe from the time that the sponges were fitted, for the determination of FSH.

\section{Experiment 2}

The aim of Exp. 2 was to examine further the effects of the time and duration of oestradiol implantation on the circulating concentrations of $\mathrm{LH}$ and FSH during the follicular and luteal phases of the oestrous cycle.

Animals and treatment groups. Mature Merino ewes $(\mathrm{N}=40)$ were randomized into 4 groups. As in Exp. 1 , intravaginal progestagen-impregnated sponges were fitted to synchronize oestrus. The sponges remained in place for 12 days. For Group L, subcutaneous oestradiol implants were inserted for the final 2 days before sponge removal and served to examine the effects of oestradiol during the luteal phase. In Group F, oestradiol implants were inserted at the time of sponge removal and remained in place through ovulation to examine the effects of oestradiol during the follicular phase. Group $L+F$ ewes received oestradiol implants during both the luteal and follicular phases and the Group C (control) ewes had empty implants inserted 2 days before sponge removal and left in place until ovulation. 
The implants used in this experiment were $10 \mathrm{~mm}$ in length and were prepared as in Exp. 1 . The length of the implant was greater than for those used in Exp. 1 because the duration of implantation was decreased. At 7 days after the sponges were removed, the ovaries of all ewes were examined by laparoscopy under local anaesthesia.

Blood sampling for hormone analysis. Blood was sampled from all ewes at 4-h intervals for 4 days, from 2 days before until 2 days after the removal of the progestagen sponges. These samples were analysed for FSH.

Superimposed on this regimen were two periods of intensive sampling for determining the pattern of LH secretion. In the first period, on the day before the removal of the intravaginal sponges samples were collected at 20 -min intervals for $12 \mathrm{~h}$ and were representative of the luteal phase. In the second period, on the day after the removal of the progestagen sponges, samples were collected at 10-min intervals for $4 \mathrm{~h}$ and were representative of the follicular phase.

\section{Hormone assays}

All samples were assayed for $\mathrm{LH}$ using a double-antibody radioimmunoassay (Martin et al., 1980; Atkinson \& Williamson, 1985). Hormone preparation PNRS-M3 (M. Jutisz, College de France) was used for reference and iodination. The sensitivity of the assay was $0.035 \mathrm{ng} /$ tube and non-specific binding was $<3 \%$. Two plasma pools containing $17.36 \pm 0.37$ and $8.52 \pm 0.19 \mathrm{ng} \mathrm{LH} / \mathrm{ml}$ were included in each assay for the calculation of the inter-assay coefficients of variation which were $12.4 \%$ and $13.8 \%$, respectively. Intra-assay coefficient of variation was $6.9 \%$.

Samples were assayed for FSH using a double-antibody radioimmunoassay provided by the pituitary agency of NIH and validated in our laboratory (Atkinson \& Adams, 1988). Preparations NIAMDD-oFSH-RP-1 and NIAMDD-oFSH-I-1 were used for reference and iodination, respectively. Non-specific binding in the assay was $1.54 \pm 0.12 \%$ and the sensitivity of the assay was $0.09 \mathrm{ng} /$ tube. Two plasma pools containing $0.83 \pm 0.03$ and $1.99 \pm 0.04 \mathrm{ng} \mathrm{FSH} / \mathrm{ml}$ were included in each assay for the calculation of the inter-assay coefficients of variation, which were $17.9 \%$ and $10.0 \%$, respectively. Intra-assay coefficient of variation was $8.6 \%$.

\section{Data analysis}

Ovulation rates were compared using a $\chi^{2}$ analysis with the control ovulation rate as the expected value. Log-logit transformations were applied to the standard curves of the assays (Rodbard, 1974). The pulse frequency of LH was expressed as the mean number of peaks per group over $8 \mathrm{~h}$ and was determined using the 'Munro' pulse analysis program (Martin et al., 1987). The $G$ parameters, or number of standard deviations by which a pulse must exceed the baseline, were $3 \cdot 0,2 \cdot 4,2 \cdot 0,1 \cdot 5$ and $1 \cdot 2$ for pulses composed of $1-5$ samples, respectively. The Baxter parameters, or values needed to describe mathematically the relationship between the concentration of LH and the assay variation were $0.2138(y$ intercept $), 0.00359$ ( $x$ coefficient), and $0.0029\left(x^{2}\right.$ coefficient). Data for FSH were normalized by transformation to $\log (x+1)$. The hormone data were analysed with an ANOVA comparing the affects of oestradiol and empty implants or single and twin ovulators.

\section{Results}

\section{Effect of implants}

The small oestradiol implants used in this study did not significantly affect the ovulation rate. In Exp. 1, the ovulation rate for the implanted and control groups were 1.38 and 1.47 respectively. In Exp. 2, the ovulation rate for Groups L, F, L + F, and C were 1.53, 1.48, 1.41 and 1.47, respectively.

Implants reduced the frequency of LH pulses during the luteal phase of the cycle, in Exp. 1 and Exp. 2 (Fig. 1). A combined ANOVA including both experiments indicated that overall mean also differed significantly (Fig. 1). Implants did not affect the amplitude of LH pulses or the baseline concentration in either experiment. Similarly, implants did not affect the concentration of FSH in the luteal phase in either experiment.

There were fewer effects of implants on gonadotrophins during the follicular phase. In Exp. 1 there was no effect of implants on FSH or any characteristic of LH secretion $12 \mathrm{~h}$ after removal of the progestagen sponges (Fig. 2). In Exp. 2 during the follicular phase, the LH pulse frequency was lower in ewes of Groups L, F and L + F than in Group C ewes (Fig. 2). Neither LH baseline nor the amplitude of LH pulses were different between the implanted and control groups. The overall concentration of FSH was also similar in all groups.

In Exp. 1, the preovulatory surge of LH and FSH began earlier in the control ewes than in the ewes with oestradiol implants (Fig. 3). The amplitude of the LH surge was significantly greater 


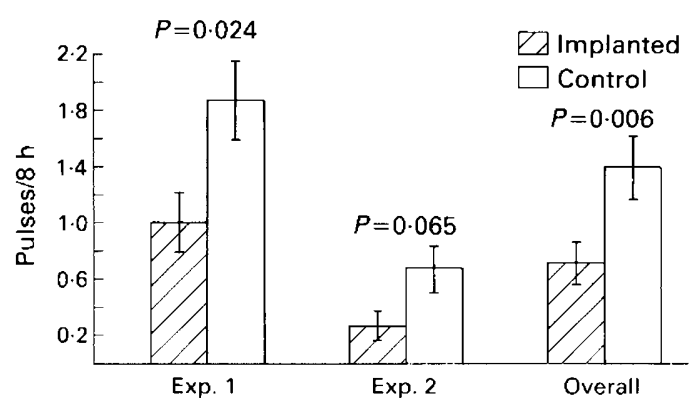

Fig. 1. Frequency of LH pulses during the luteal phase in control and oestrogen-implanted ewes. Values are mean \pm s.e.m. for 15 ewes per group in Exp. 1 and 5 ewes per group in Exp. 2.

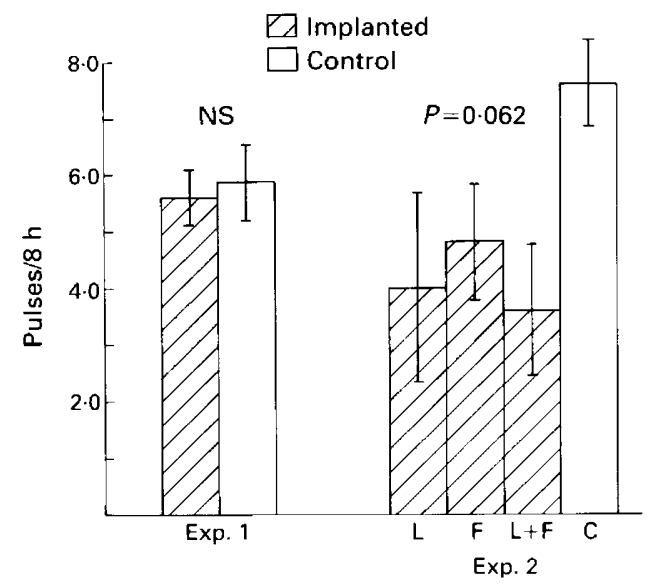

Fig. 2. Frequency of LH pulses during the follicular phase in control and oestrogen-implanted ewes. Values are mean \pm s.e.m. for 15 ewes per group in Exp. 1 and 5 ewes per group in Exp. 2.

$(P<0.01)$ in the control ewes than in the oestradiol-implanted ewes (Fig. 3a). The duration of the surges and the amplitude of the FSH surge did not differ between the two groups (Fig. 3 b).

\section{Effects of ovulation rate}

In a retrospective analysis, ewes that subsequently had twin ovulations were compared with ewes that had single ones. During the period before progestagen sponges were withdrawn (the luteal phase), ewes which twinned had higher concentrations of FSH; the differences were significant in Exp. 1 but not in Exp. 2 (Fig. 4). An ANOVA on the combined data indicated different mean FSH values for single- and twin-ovulating ewes $(P=0.018$; Fig. 4$)$. There were no significant differences between single- and twin-ovulating ewes for values of FSH in samples taken after luteolysis.

In Exp. 1, the amplitude of $\mathrm{LH}$ pulses was greater in single than in twin-ovulating ewes examined during the luteal phase $(3.40 \pm 0.23$ and $1.91 \pm 0 \cdot 14$, respectively), but this difference was not seen in Exp. 2. There were no differences between single- and twin-ovulating ewes in LH pulse frequency or LH baseline in either the luteal or follicular phases observed in either experiment. 


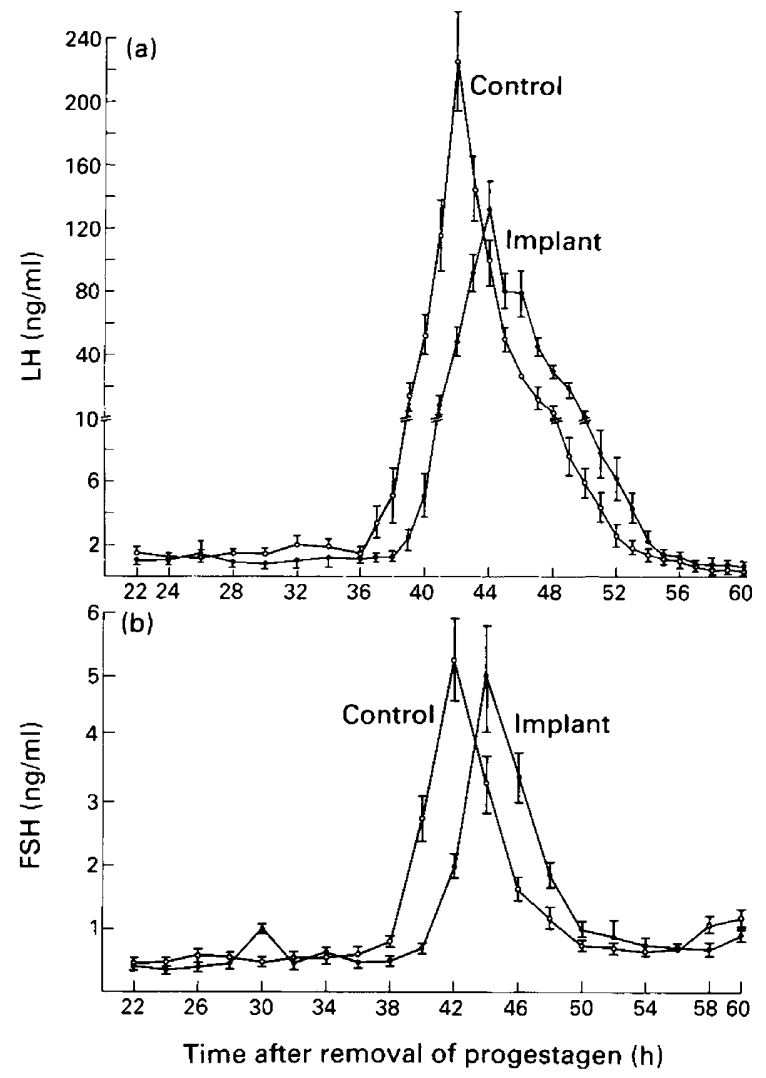

Fig. 3. Preovulatory surges of (a) LH and (b) FSH in the circulation of control and oestrogenimplanted ewes $22-60 \mathrm{~h}$ after the removal of a progestagen-impregnated sponge. Values are mean \pm s.e.m. for 15 ewes per group.

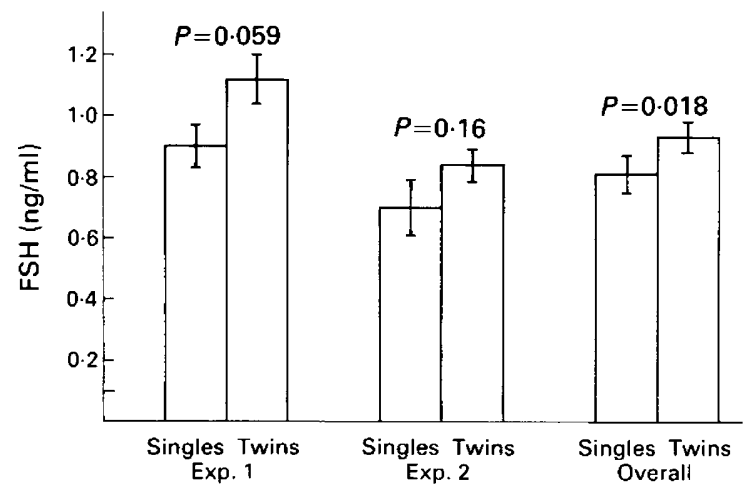

Fig. 4. Concentration of FSH during the luteal phase in ewes subsequently having single or twin ovulations. Values are mean \pm s.e.m. for 15 ewes per group in Exp. 1 and 10 ewes per group in Exp. 2. 


\section{Discussion}

This study demonstrates that exogenous oestradiol can alter the secretion of LH in the ewe without producing detectable changes in the concentration of FSH or affecting the ovulation rate. Ovarian production of oestradiol during the luteal phase is estimated to be less than $2 \cdot 2 \mu \mathrm{g} / 24 \mathrm{~h}$ (Baird \& Scaramuzzi, 1976) and approximately $6 \mu \mathrm{g} / 24 \mathrm{~h}$ at oestrus (Baird et al., 1968). The doses of oestradiol used in the present study were low $(0.57$ and $1.9 \mu \mathrm{g}$ per $24 \mathrm{~h})$ and comparable with the estimated production rates of oestradiol, so were within the physiological range. Although reliable assay data for the concentration of oestradiol are not available, this conclusion is supported by the failure of oestradiol treatment to reduce the ovulation rate.

The reduction of LH pulse frequency without an effect on ovulation rate can be explained in three ways. Firstly, the decrease in frequency may have been too small to alter the ovulation rate. The decline in frequency was around $50 \%$ and therefore this explanation appears unlikely, given that no difference in LH pulse frequency was found between single- and twin-ovulating ewes. Secondly, it could be that the increase in oestradiol produced by the implants compensated at the ovarian level for the lack of LH. This also appears unlikely, as the local concentration of oestradiol within the ovary would not be substantially increased by the amounts of oestradiol given. Thirdly, and most likely, is the possibility that LH secretion during the luteal phase may not play an important role in determining ovulation rate in the ewe. This is supported by studies comparing $\mathbf{L H}$ concentrations in standard Merino and Booroola (a fecund strain) ewes, which failed to demonstrate a relationship between LH secretion and prolificacy (Bindon, 1984). Further, the administration of exogenous $\mathrm{LH}$ to produce widely varied concentrations of $\mathrm{LH}$ in the circulation did not change ovulation rate (McNatty et al., 1981). These previous reports together with the results of the present experiments lead to the conclusion that luteal-phase LH secretion is not a major factor in the determination of ovulation rate in the ewe.

Emons et al. (1986) infused ovariectomized ewes with high doses of oestradiol or the catecholoestrogen, 4-hydroxyoestradiol, and observed that the LH surges were smaller than those in control ewes. The ewes implanted with oestradiol in Exp. 1 had preovulatory LH surges of an amplitude nearly half that of the controls. In addition, the preovulatory surges of both LH and FSH were delayed $2 \mathrm{~h}$ in the ewes implanted with oestradiol. Thus, both the pulse frequency during the luteal phase and the gonadotrophin surges were sensitive to the actions of physiological concentrations of exogenous oestradiol.

Very few differences were observed in the gonadotrophin profiles of ewes which subsequently had single or twin ovulations. The decreased LH pulse amplitude during the luteal phase in the twinning ewes in Exp. 1 was not observed in Exp. 2, and may be attributed to chance due to the low number of pulses recorded. In both experiments, the ewes which subsequently had twin ovulations had slightly higher concentrations of FSH during the luteal phase than did ewes with single ovulations, an effect revealed as significant when the data were combined. A similar difference was not evident in the follicular phase. McNatty et al. (1985) reported that animals with twin ovulations had higher concentrations of FSH during the previous luteal phase than did animals with single ovulations. Furthermore, fecund Booroola ewes have higher plasma concentrations of FSH during the oestrous cycle than do standard Merino ewes (Bindon, 1984). However, the difference in FSH concentrations between ewes bearing single and twin ovulations was so small in the present study that the combined data for 60 animals were needed before the difference became statistically significant. It is therefore difficult to postulate a principal role for FSH in the final selection of the dominant follicle in the ewe. It is possible that the differences observed in this and other studies may reflect the response of FSH to other factors which are, as yet, unidentified.

The effects of exogenous oestradiol on LH pulse frequency were observed while the ewes were under the influence of the intravaginal progestagen sponges, and also within $24 \mathrm{~h}$ of the removal of the sponges. This indicates that the hypothalamo-hypophysial axis was responding to the negative feedback effects of oestradiol (known to occur in the presence of progesterone) (Baird \& 
Scaramuzzi, 1976; Hauger et al., 1977), and it was also responding after the oestradiol had been removed. This was apparent in the ewes in Exp. 2 that were given implants during the luteal phase and had reduced LH-pulse frequencies during the follicular phase, even though the implants had been removed (see Group L, Fig. 2). This carry-over effect could be due to the oestradiol remaining in the circulation and continuing to affect LH pulsatility. Alternatively, the carry-over effect may result from a long-term delay in the recovery of the hypothalamo-hypophysial axis from the inhibitory effects of oestradiol. The metabolic clearance rate of oestradiol in the circulation is rapid (Challis et al., 1973), and so the latter explanation is most likely. A similar carry-over effect was also observed on a larger scale when oestradiol implants suppressed the ovulation rate of ewes for at least one subsequent cycle ( $\mathrm{S}$. Atkinson \& N. R. Adams, unpublished data). The doses of oestradiol used in those experiments were considerably larger, suggesting that the carry-over effect may be dose-dependent, or that exogenous oestradiol can alter ovulation rate by some means other than by changing $\mathrm{LH}$ pulse frequency.

We thank the National Hormone and Pituitary Program, NIADDK, Bethesda, Maryland, USA, for the FSH antiserum and standard and Professor M. Jutisz of the College de France (Paris) for the LH preparation; M. Sanders, J. Briegel, J. Abordi, D. Suckling and J. Smith for technical assistance; and Ms D. Chandler for typing the manuscript. Part of the work was supported by the Australian Wool Corporation.

\section{References}

Atkinson, S. \& Adams, N.R. (1988) Adrenal glands alter the concentration of oestradiol-17 $\beta$ and its receptor in the uterus of ovariectomized ewes. $J$. Endocr. 118, 375-380.

Atkinson, S. \& Williamson, P. (1985) Ram-induced growth of ovarian follicles and gonadotrophin inhibition in anoestrous ewes. J. Reprod. Fert. 73, 185-189.

Baird, D.T. \& Scaramuzzi, R.J. (1976) Changes in the secretion of ovarian steroids and pituitary luteinizing hormone in the peri-ovulatory period in the ewe: the effect of progesterone. J. Endocr. 70, 237-245.

Baird, D.T., Goding, J.R., Ichikawa, Y. \& McCracken, S.A. (1968) Secretion of steroids from the autotransplanted ovary in the ewe spontaneously and in response to systemic gonadotrophin. J. Endocr. 42, 283-299.

Bindon, B.M. (1984) Reproductive biology of the Booroola Merino sheep. Aust. J. biol. Sci. 37, $163-189$.

Challis, J.R.G., Harrison, F.A. \& Heap R.B. (1973) The kinetics of oestradiol-17 $\beta$ metabolism in the sheep. $J$. Endocr. 57, 97-110.

Emons, G., Schuppe, H., Peter, M., Brack, C. \& Ball, P. (1986) Modulation of $\mathbf{L H}$ secretion in ovariectomized ewes by constant infusions of oestradiol and 4hydroxyoestradiol: effect of varying infusion times and of high oestrogen doses. Acta endocr., Copenh. 113, 219-225.

Findlay, J.K. \& Cumming, I. (1976) FSH in the ewe: Effects of season, live weight and plane of nutrition on plasma FSH and ovulation rate. Biol. Reprod. 15, 335-342.

Haresign, W. (1981) The influence of nutrition on reproduction in the ewe. I. Effects on ovulation rate, follicle development and luteinizing hormone release. Anim. Prod. 32, 197-202.

Hauger, R.L., Karsch, F.J. \& Foster, D.L. (1977) A new concept for control of the estrous cycle of the ewe based on the temporal relationships between luteinizing hormone, estradiol and progesterone in peripheral serum and evidence that progesterone inhibits tonic LH secretion. Endocrinology 101, 807-817.

Martin, G.B., Oldham, C.M. \& Lindsay, D.R. (1980) Increased plasma LH levels in seasonally anovular merino ewes following the introduction of rams. Anim. Reprod. Sci. 3, 125-132.

Martin, G.B., Scaramuzzi, R.J. \& Henstridge, J.D. (1983) Effects of oestradiol, progesterone and androstenedione on the pulsatile secretion of luteinizing hormone in ovariectomized ewes during spring and autumn. $J$. Endocr. 96, 181-193.

Martin, G.B., Taylor, P.L. \& McNeilly, A.S. (1987) Effect of small doses of bovine follicular fluid on the tonic secretion of gonadotrophins in the ewe. $J$. Endocr. 114, 73-79.

McNatty, K.P., Gibb, M., Dobson, C. Thurley, D.C. (1981) Evidence that changes in luteinizing hormone secretion regulate the growth of the preovulatory follicle in the ewe. J. Endocr. 90, 375-389.

McNatty, K.P., Hudson, N., Gibb, M., Ball, K., Henderson, K.M., Heath, D.A., Lun, S. \& Kieboom, L.E. (1985) FSH influences follicle viability, oestradiol synthesis and ovulation rate in Romney ewes. $J$. Reprod. Fert. 75, 121-131.

Pathiraja, N., Carr, W.R., Fordyce, M., Forster, J., Land, R.B. \& Morris, B.A. (1984) Concentration of gonadotrophins in the plasma of sheep given gonadal steroid antisera to raise ovulation rate. J. Reprod. Fert. 72, 93-100.

Rhind, S.M. \& McNeilly, A.S. (1986) Effects of body 
condition on ovulation rate and associated plasma levels of LH, FSH and prolactin in the ewe. Anim. Reprod. Sci. 10, 105-115.

Rhind, S.M., Doney, J.M., Gunn, R.G. \& Leslie, I.D. (1984) Effects of body condition and environmental stress on ovulation rate, embryo survival, and associated plasma follicle stimulating hormone, luteinizing hormone, prolactin and progesterone profiles in Scottish blackface ewes. Anim. Prod. 38, 201-209.

Rhind, S.M., Leslie, I.D., Gunn, R.G. \& Doney, J.M. (1986) Effects of high levels of body condition and food intake on plasma follicle stimulating hormone, luteinizing hormone, prolactin and progesterone profiles around mating in Greyface ewes. Anim. Prod. 43, 101-107.

Rodbard, D. (1974) Statistical quality control and routine data processing for radioimmunoassays and immunoradiometric assays. Clin. Chem. 20, 1255-1270.
Scaramuzzi, R.J. \& Radford, H.M. (1983) Factors regulating ovulation rate in the ewe. J. Reprod. Fert. 69, 353-367.

Thomas, G.R., Oldham, C.M. \& Martin, G.B. (1984) Frequency of luteinizing hormone release in Merino ewes with one and two ovulations. In Reproduction in Sheep, pp. 102-104. Eds D. R. Lindsay \& D. T. Pearce. Australian Academy of Science, Canberra.

Wallace, J., McNeilly, A.S. \& Baird, D.T. (1985) Ovulation rate and embryo survival in Damline ewes after treatment with bovine follicular fluid in the luteal phase of the oestrous cycle. J. Reprod. Fert. 75, 101-109.

Webb, R. \& Gauld, I.K. (1987) Endocrine control of follicular growth in the ewe. In Follicular Growth and Ovulation Rate in Farm Animals, pp. 107-118. Eds J. F. Roche \& D. O'Callaghan. Martinus Nijhoff, Dordrecht.

Received 3 October 1988 